\title{
CORRECTION
}

View Article Online

View Journal I View Issue

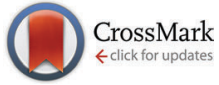

Cite this: New J. Chem., 2015, 39, 1526

DOI: 10.1039/c4nj90051k

www.rsc.org/njc

\section{Correction: Extraction and electrochemical detection of capsaicin and ascorbic acid from fresh chilli using ionic liquids}

\author{
Benjamin B. Y. Lau, Janjira Panchompoo and Leigh Aldous*
}

Correction for 'Extraction and electrochemical detection of capsaicin and ascorbic acid from fresh chilli using ionic liquids' by Benjamin B. Y. Lau et al., New J. Chem., 2015, DOI: 10.1039/c4nj01416b.

Due to an editorial error, Fig. 8 is incorrect in the published article. The correct Fig. 8 is shown below.

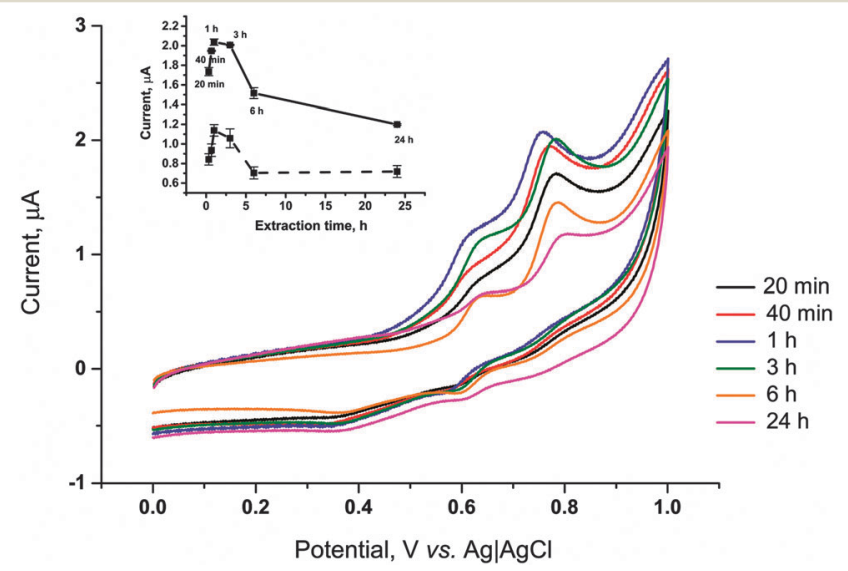

Fig. 8 Overlaid cyclic voltammograms of $1 \mathrm{~g}$ of fresh chilli extracted in $0.1 \mathrm{M}$ [Emim] [OAc] at $50{ }^{\circ} \mathrm{C}$ for a range of times ( $20 \mathrm{~min}$ to $24 \mathrm{~h}$ ), recorded at a GC electrode in a $0.1 \mathrm{M}$ [Emim] [OAc] - water/ethanol $60 / 40 \% \mathrm{v} / \mathrm{v}$ mixture containing $0.2 \mathrm{M} \mathrm{HCl}$. Inset plot of peak current vs. chilli extraction time for the reduction peaks of capsaicin (solid) and ascorbic acid (dashed).

The Royal Society of Chemistry apologises for these errors and any consequent inconvenience to authors and readers. 